\title{
Porcine vs bovine surfactant therapy for preterm neonates with RDS: systematic review with biological plausibility and pragmatic meta-analysis of respiratory outcomes
}

Ascanio Tridente ${ }^{1,2}$, Lucia De Martino ${ }^{3}$ and Daniele De Luca ${ }^{3,4^{*}}$ (D)

\begin{abstract}
Background: Bovine surfactants are known to be clinically equivalent but it is unclear if porcine or bovine surfactants at their licensed dose should be preferred to treat respiratory distress syndrome in preterm neonates.

Methods: We performed a comprehensive review of biochemical and pharmacological features of surfactants to understand the biological plausibility of any clinical effect. We then performed a pragmatic meta-analysis comparing internationally marketed porcine and bovine surfactants for mortality and respiratory outcomes. Search for randomised controlled trials with no language/year restrictions and excluding "grey" literature, unpublished or non-peer reviewed reports was conducted, following Preferred Reporting Items for Systematic Reviews and Meta-Analyses guidelines and the most recent methodological recommendations.
\end{abstract}

Results: Sixteen articles were included in the review and 14 in the meta-analysis (1491 neonates). $200 \mathrm{mg} / \mathrm{kg}$ poractant-a (a porcine surfactant) was associated with lower BPD/mortality (OR 0.632[95\%Cl:0.494, 0.809]; $p<0.001), B P D$ (OR 0.688[95\%Cl:0.512, 0.925]; $p=0.013$ ), retreatment (OR 0.313[95\%Cl:0.187, 0.522]; $p<0.0001$ ), airleaks (OR 0.505[95\%Cl: $0.308,0.827] ; p=0.006$ ) and lung haemorrhage (OR 0.624[95\%Cl:0.388, 1]; $p=0.051)$. Gestational age is associated with effect size for BPD (coefficient: 0.308 [95\%Cl:0.063, 0.554]; $p=0.014$ ) and surfactant retreatment (coefficient: -0.311 [95\%Cl:-0.595, - 0.028]; $p=0.031)$.

Conclusion: $200 \mathrm{mg} / \mathrm{kg}$ poractant-a is associated with better respiratory outcomes compared to bovine surfactants at their licensed dose. The effect of poractant-a on BPD and surfactant retreatment is greater at lowest and highest gestational ages, respectively.

Trial registration: PROSPERO n.42017075251.

Keywords: RDS, Neonate, Surfactant, Therapy

\footnotetext{
* Correspondence: daniele.deluca@aphp.fr

${ }^{3}$ Division of Pediatrics and Neonatal Critical Care, Medical Center "A. Béclère",

South Paris University Hospitals, Assistance Publique-Hôpitaux de Paris

(APHP), Paris, France

${ }^{4}$ Physiopathology and Therapeutic Innovation Unit, INSERM U999, South

Paris-Saclay University, Paris, France

Full list of author information is available at the end of the article
}

(c) The Author(s). 2019 Open Access This article is distributed under the terms of the Creative Commons Attribution 4.0 International License (http://creativecommons.org/licenses/by/4.0/), which permits unrestricted use, distribution, and 


\section{Background}

Respiratory distress syndrome (RDS) is the main cause of respiratory failure in preterm neonates and its incidence differs depending on gestational age and birth weight [1]. RDS was originally known as "hyaline membrane disease", based on its histological appearance [2] and re-named RDS after the acceptance that it was caused by primary surfactant deficiency [3].

When optimal prenatal care is provided, the best approach to treat RDS, according to several recent trials, [4] consists in providing continuous positive airway pressure from the first minutes of life using short binasal prongs, [5] followed by early selective surfactant administration for babies with worsening oxygenation and/or increasing work of breathing. Both European and American guidelines advise in favour of this strategy, which reduces mortality and broncho-pulmonary dysplasia (BPD) [6, 7]. Nevertheless, it remains unclear whether the use of different surfactants might influence the outcomes. Currently available surfactants are animal-derived preparations. They resulted to be superior to older synthetic (protein-free) surfactants, as the proteins improve surfactant activity, stabilizing the film at the air/liquid interface [8]. Animal-derived surfactants may carry pharmacological and biochemical differences and these latter might influence clinical outcomes.

A 2015 Cochrane meta-analysis subdivided surfactants in bovine and porcine-derivedand according to the extraction method (lung lavage or minced lung extract): [9] neonates treated with porcine minced surfactant had more favourable outcomes than those treated with bovine minced lung surfactant. The meta-analysis did not identify any significant difference between bovine lung lavage and bovine minced lung-derived surfactant [9]. Other comparisons between different surfactants were either based on a single trial or not feasible, due to lack of studies [9].

Our aim was to: 1) comprehensively review all the pharmacological and biochemical differences between available animal-derived surfactants, and 2) compare porcine and bovine surfactants with regard to mortality and respiratory outcomes in preterm neonates with RDS.

Such a pragmatic meta-analysis was limited to randomised controlled trials investigating the use of internationally available surfactants; since no significant differences have been detected between bovine surfactants of different extraction method (minced or lung lavage), [9] porcine surfactants were compared to all bovine surfactants, irrespective of their method of preparation.

\section{Methods}

\section{Protocol}

Prior to commencing the search, a systematic review protocol was agreed to determine the databases to be searched, search modality, eligibility criteria, data extraction/aggregation methodology, timing of meetings and methods for dispute resolution in case of disagreement. Following the agreement, this review was registered in the international prospective register of systematic review (PROSPERO n.42017075251). Regular meetings between the authors were scheduled and the Preferred Reporting Items for Systematic Reviews and Meta-Analyses guidelines were followed through the entire project [10].

\section{Review of the pharmacological and biochemical surfactant features}

We obtained pharmacological and biochemical data from previous publications in the field [11-15] and by systematically looking within the product leaflets and the manufacturer websites. When in doubt or when informations were lacking, we contacted directly the manufacturer or, in case of no answer, the dealer and/or authors of related papers. At least two e-mails have been sent before writing to the alternative contact.

\section{Eligibility criteria}

We looked for randomized controlled trials fulfilling the following criteria: 1) published as full articles or as abstracts presented at the Paediatric Academic Societies (PAS) or European Society for Paediatric Research (ESPR) meetings; 2) enrolled preterm neonates (gestational age $<37$ weeks) with clinical and/or radiological established evidence of RDS needing intubation; 3) compared porcine and bovine-derived surfactants (irrespective of their preparation method); and 4) reported at least one of the selected outcomes (see below).

Studies fulfilling these criteria were finally included in the meta-analysis, if they compared surfactants internationally available on the market. Since early selective surfactant treatment is currently advised by international guidelines, [6,7] we did not consider trials on surfactant prophylaxis (i.e. with surfactant administered without any evidence of RDS, in the first minutes of life). No language or year restrictions were applied. We excluded "grey" literature, unpublished or non-peer reviewed reports.

\section{Information sources and search strategy}

We conducted a literature search (on June 25, 2018) of the following databases: AMED, BNI, CINAHL, EMBASE, HBE, HMIC, Medline, PsycINFO, PubMed, using the NICE National Institute for Healthcare Excellence Healthcare Databases Advanced Search portal. We used the following as key words and/or MeSH terms: "treatment", "bovine lipid extract surfactant", "BLES", "beractant", "survanta", "surfacen", "surfactant-TA", "surfacten", "bovactant", "alveofact", "calfactant", "infasurf", "poractant alfa", "curosurf", "newfactant". We searched 
the abstract archives of the PAS and ESPR meetings and the clinicaltrials.gov registry. We also hand-searched references cited in the studies identified through the initial search, review articles on the subject and the authors' personal archives. Finally, we contacted experts in the field and letters commenting the trials have also been reviewed.

We used the following string: (treatment AND ((((bovine AND lipid) AND extract) AND surfactant) OR BLES OR beractant OR survanta OR surfacen OR surfactant-TA OR surfacten OR bovactant OR alveofact OR calfactant OR infasurf OR poractant alfa OR curosurf OR newfactant)).ti,ab.

\section{Study selection}

Details of all studies retrieved were included in a database, removing duplicates. All authors reviewed abstracts, and (where necessary) full text of the remaining articles, excluding those not meeting the eligibility criteria.

\section{Data collection process}

We developed a data extraction sheet (based on the Cochrane Consumers and Communication Review Group's data extraction template), pilot-tested it on three randomly-selected studies, and refined it accordingly. Data from included trials were extracted independently by two authors (AT, DDL) and then cross-verified. Discrepancies were resolved through discussion between the two reviewers and, if no agreement could be reached, with the third investigator. Where further clarification was needed or when data could not be statistically aggregated authors were contacted to provide clarification and/or raw data.

\section{Data items}

Data collected included study design, number of enrolled patients, prenatal corticosteroid, mean gestational age, inclusion and exclusion criteria, surfactant type and doses, outcomes and variables used to assess study quality.

The outcomes were: 1) in-hospital mortality; 2) BPD defined as need for supplemental oxygen at postmenstrual age of 36 weeks or, if this latter was unavailable, at 28 days of postnatal age; 3 ) composite $\mathrm{BPD} /$ mortality endpoint; 4) air leaks defined as occurrence of pneumothorax, pneumomediastinum and/or pulmonary interstitial emphysema occurring after surfactant administration; 5) surfactant re-treatment; 6) lung haemorrhage defined as bright red blood in the endotracheal tube, with rapid deterioration of the clinical and/or respiratory status, occurring after surfactant administration.

\section{Assessment of risk of Bias}

The Cochrane Risk of Bias assessment tool [16] was used to evaluate the study quality. Two reviewers (AT,DDL) independently assessed the risk of bias for each trial, including: 1) selection bias (inadequate random sequence generation, failure to conceal treatment allocation); 2) performance bias (inadequate blinding of patients and investigators/personnel); 3) detection bias (failure to adequately blind the outcome assessors); 4) attrition bias (incomplete outcome data evaluation and failure to follow intention-to-treat analysis); 5) reporting bias (selective outcome reporting); 6) any other bias and any potential conflict of interest.

Each item was assessed as at "low" or "high risk" of bias, or unclear (when the authors were unable to determine, on the basis of the available information). Discrepancies were resolved through discussion between the two reviewers and, if no agreement could be reached, with the third investigator. The presence of publication bias was explored through: 1) visual assessment of a Funnel plot; 2) Egger regression and 3) Peters' test, according to recent published recommendations [17]. More details are available in the Additional file 1.

\section{Summary measures and synthesis of results}

We performed the following analyses: 1) $200 \mathrm{mg} / \mathrm{kg}$ poractant- $\alpha$ versus $100 \mathrm{mg} / \mathrm{kg}$ bovine surfactants; and 2) any dose of poractant- $\alpha$ versus $100 \mathrm{mg} / \mathrm{kg}$ bovine surfactants (that is, pooling the data from all treatment arms in which poractant- $\alpha$ was administered, irrespective of the dosage used). We did not perform a separate analysis of $100 \mathrm{mg} / \mathrm{kg}$ poractant- $\alpha$ versus $100 \mathrm{mg} / \mathrm{kg}$ bovine surfactants, since this would have been unreliable because only based on 2-3 trials and smaller patient populations.

Outcomes were analysed using weighted average odds ratios (OR) and 95\% confidence interval (95\% CI) for all outcomes. We used the DerSimonian-Laird random-effects model and inverse variance method. Such approach is more conservative than the fixed effect model as, it assumes the presence of heterogeneity among aggregated studies, based on the assumption that the studies considered are estimating different underlying effect sizes [18]. Consistency across the studies was evaluated using the $I^{2}$ statistic (variation in ORs attributable to heterogeneity) and performing a $X^{2}$ test for heterogeneity; an $I^{2}$ value greater than $50 \%$ was considered as indicative of substantial heterogeneity.

\section{Additional analyses}

Antenatal steroid prophylaxis might be a relevant confounding bias for our outcomes, as it boosts the production of endogenous surfactant [19]. Studies have been published across several years (from 1995 to 2017), that is also before the widespread use of prenatal steroids in common clinical practice: thus, steroids have been 
variously administered amongst the studies. RDS is also known to be more severe at lower gestational ages [20,21] and this may be another confounder.

Finally, poractant- $\alpha$ dose can be a confounder, since this is the only surfactant with two licensed doses and can be administered at 100 or $200 \mathrm{mg} / \mathrm{kg}$. Thus, we performed three random-effects model meta-regressions per each clinical outcome [22] and we inserted as covariates: 1) the use of antenatal steroids (as \% of neonates treated in each study), 2) the gestational age (as mean gestational age (in weeks) of each study population), and 3 ) the dose of poractant- $\alpha$ administered in each study. We only used one covariate in each model in order to reduce false positive conclusions [22]. Coefficients (and $95 \% \mathrm{CI}$ ) have been reported for each covariate. All analyses were performed with SPSS 15.0 (SPSS inc, Chicago, IL, USA), Open-MetaAnalyst 10.1 [23] and Meta-essentials [24].

\section{Results}

Table 1 describes the biochemical and pharmaceutical features of all animal-derived surfactants currently available to treat RDS in preterm neonates. There is a wide variation in phospholipid profile amongst surfactants. Surfactant-protein content is also variable and poractant $\alpha$ is the preparation with the highest protein concentrations (especially of surfactant protein-B). All surfactant but poractant- $\alpha$ have similar formulation in terms of phospholipid concentration (roughly about 30 $\mathrm{mg} / \mathrm{mL}$ ). Poractant- $\alpha$ shows a concentration of $80 \mathrm{mg} /$ $\mathrm{mL}$.

Figure 1 illustrates the study selection for the metaanalysis: three studies were excluded for data duplication, methodological flaws and/or non-eligibility [2527]. Of note, we did not find any trial investigating the use of the Chinese surfactant, while all other surfactants have been subjected to at least one trial. Characteristics of each included trial are summarized in the Additional file 1 . We found 16 trials [28-43] but only 14 were finally included in the meta-analysis [28-41]. Five comment letters were also reviewed [44-48]. All studies compared a porcine surfactant with beractant, bovactant or BLES. No studies compared porcine surfactants with calfactant, Korean bovine surfactant or surfactant-TA.

Fifteen out of sixteen papers were in English, one was in Spanish [43] and was evaluated without translation,

Table 1 Biochemical and pharmacological data of all current animal-derived surfactant preparations

\begin{tabular}{|c|c|c|c|c|c|c|c|c|}
\hline & Biochemical (trade) name & $\begin{array}{l}\text { Preparation } \\
\text { method }\end{array}$ & $\begin{array}{l}\text { Total PL } \\
(\mathrm{mg} / \mathrm{mL})\end{array}$ & Main $\mathrm{PL}^{\circ}$ & $\begin{array}{l}\text { SP-B } \int \\
(\mathrm{mg} / \mathrm{mL})\end{array}$ & $\begin{array}{l}\mathrm{SP}-\mathrm{C} \int \\
(\mathrm{mg} / \mathrm{mL})\end{array}$ & $\begin{array}{l}\text { Dose \# } \\
(\mathrm{mg} / \mathrm{mL})\end{array}$ & $\begin{array}{l}\text { Volume } \\
(\mathrm{mL} / \mathrm{kg})\end{array}$ \\
\hline \multirow[t]{7}{*}{ Bovine } & Beractant (Survanta ${ }^{\circledR}$ ) & $\begin{array}{l}\text { Enriched minced } \\
\text { lungt }\end{array}$ & 25 & $\begin{array}{l}\text { DPPC (70\%) and } \\
\text { PS (4\%) }\end{array}$ & 0.03 & 0.3 & 100 & 4 \\
\hline & BLES (Neosurf ${ }^{\circledR}$ or Liposurf ${ }^{\circledR}$ ) & Lung lavage & 27 & $\begin{array}{l}\text { DPPC (42\%) and } \\
\text { PG (11\%) }\end{array}$ & 0.17 & 0.49 & 135 & 5 \\
\hline & Bovactant (Alveofact ${ }^{\oplus}$ ) & Lung lavage & 45 & $\begin{array}{l}\text { DPPC (39\%) and } \\
\text { PG (8.5\%) }\end{array}$ & 0.3 & 0.7 & 50 & 1.2 \\
\hline & Calfactant (Infasurf ${ }^{\circledR}$ ) & $\begin{array}{l}\text { Lung lavage } \\
\text { (from calves) }\end{array}$ & 35 & $\begin{array}{l}\text { DPPC (41\%) and } \\
\text { PG (6\%) }\end{array}$ & 0.26 & 0.36 & 105 & 3 \\
\hline & $\begin{array}{l}\text { Calf Pulmonary Surfactant for } \\
\text { Injection }\left(\text { Kelisu }^{\circledast}\right)^{\$}\end{array}$ & $\begin{array}{l}\text { Lung lavage } \\
\text { (from calves) }\end{array}$ & 30 & $\begin{array}{l}\text { DPPC } 48 \% \\
\text { other data n.a. }\end{array}$ & 0.2 & 0.25 & 100 & 3.3 \\
\hline & $\begin{array}{l}\text { Korean bovine surfactant } \\
\left(\text { Newfactan }{ }^{\circledR}\right)\end{array}$ & Minced lung & 25 & $\begin{array}{l}\text { DPPC (60\%) and } \\
\text { PG }(6 \%)\end{array}$ & $@$ & @ & 120 & 4.8 \\
\hline & Surfactant-TA (Surfacten ${ }^{\circledR}$ ) & $\begin{array}{l}\text { Enriched minced } \\
\text { lungt }\end{array}$ & 25 & $\begin{array}{l}\text { DPPC }(65 \%) \\
\text { other data n.a. }\end{array}$ & n.a. & n.a. & 120 & 4.8 \\
\hline \multirow[t]{3}{*}{ Porcine } & Butantan $\$$ & Minced lung & 25 & $\begin{array}{l}\text { DPPC }(76 \%) \\
\text { and PE }(7 \%)\end{array}$ & $\wedge$ & $\wedge$ & 100 & 4 \\
\hline & Poractant-a (Curosurf ${ }^{\circledR}$ ) & $\begin{array}{l}\text { Modified minced } \\
\text { lung* }\end{array}$ & 80 & $\begin{array}{l}\text { DPPC (46\%) and } \\
\text { PE (6\%) }\end{array}$ & 0.45 & 0.9 & 100 or 200 & 1.25 or 2.5 \\
\hline & Surfacen $\$$ & Lung lavage & 25 & $\begin{array}{l}\text { DPPC (45\%) and } \\
\text { PI (12\%) }\end{array}$ & $\pi$ & $\pi$ & 100 & 4 \\
\hline
\end{tabular}

Data have been rounded to the closest decimal; some data represent an average of the different values available and should be considered as an estimation. \$Kelisu, Butantan and Surfacen are only marketed in China, Brasil and Cuba, respectively. +Minced lung is subjected to DPPC addition and the preparation method is analogous, which makes these two surfactants similar. @All surfactant proteins in Newfactant represent $1.1 \pm 0.17$ of the total. $\wedge$ Protein B and C in Butantan represent $5-10 \%$ of the total; $\pi$ All surfactant proteins in Surfacen represent $1 \%$ of the total. No more details were available for these three surfactants (Newfactant, Butantan and Surfacen); protein content in Newfactant, Butantan and Surfacen is not expressed in $\mathrm{mg} / \mathrm{mL}$ of the final solution, thus it is not comparable to that of other surfactants. The manufacturer of surfactant-TA refused to disclose additional details. * Modification consists in concentration by liquid gel chromatography. ${ }^{\circ} \mathrm{DPPC}$ is expressed as \% of PC (with the exception of Kelisu where it is expressed as \% of the total phospholipids), while other phospholipids are expressed as \% to the total mass of surfactant. $\int$ Surfactant proteins are expressed as $\mathrm{mg} / \mathrm{mL}$ of final surfactant solution in the vial, normalized for the DPPC concentration (with the exception of Newfactant, Butantan and Surfacen - see above). \#This is intended as the licensed dose for surfactants commercially available on the international market and as a suggested dose for Butantan and Surfacen which are available in Brazil and Cuba, respectively. Abbreviations: $P L$ phospholipids, SP-B surfactant protein-B, SP-C surfactant protein-C 


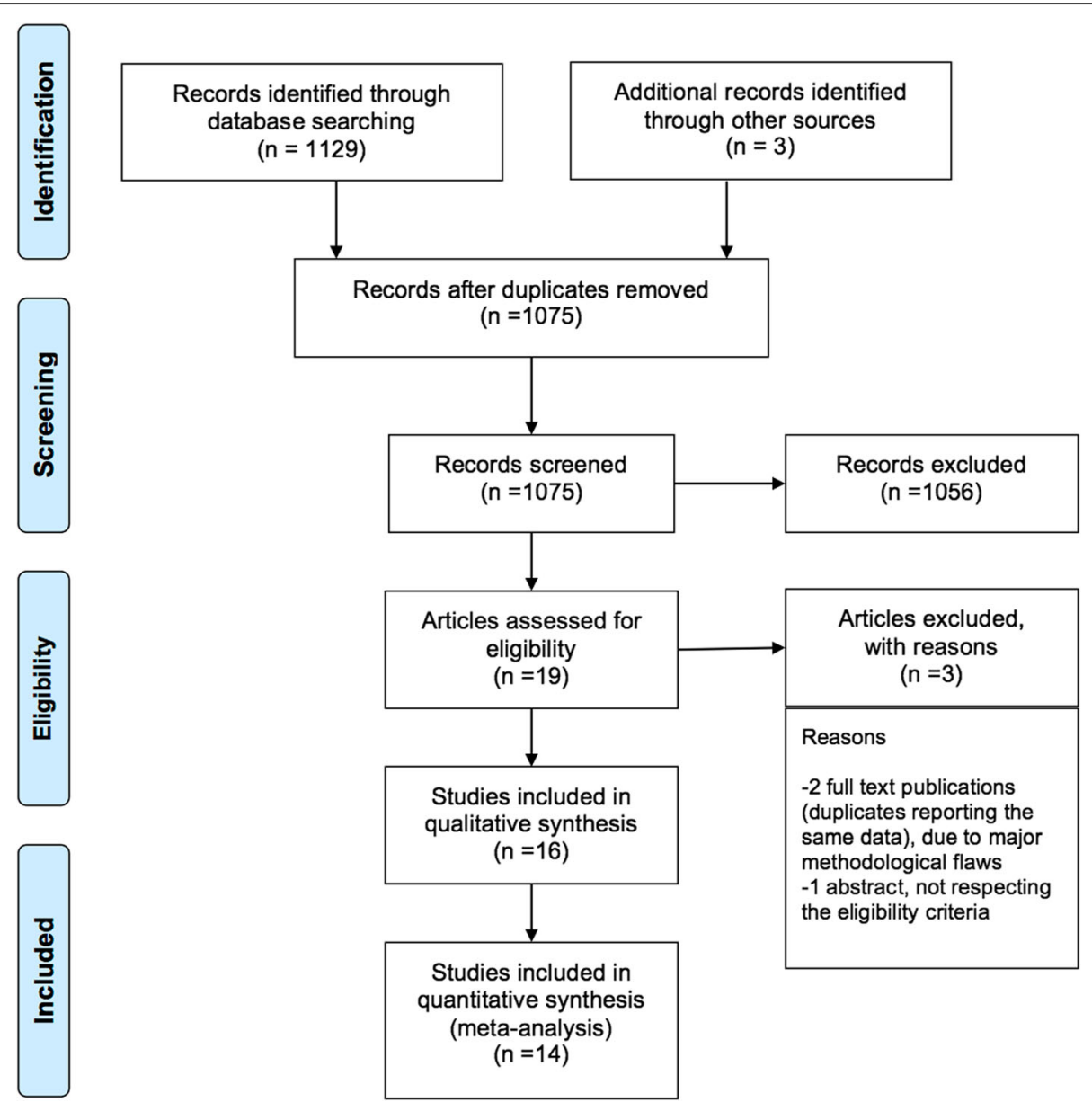

Fig. 1 Flow chart of the review. The studies excluded from the systematic review were two full text duplicates [24, 25] reporting the same data with major methodological flaws (lack of randomization, unclear analysis, lack of allocation concealment and blinding, unclear sample size calculation, unclear outcome definition and incomplete outcome analysis/reporting) and one abstract which did not respect the eligibility criteria [22]. Two studies $[42,43]$ included in the systematic review were excluded from the meta-analysis because they investigated the use of noninternationally available porcine surfactants

since two authors (AT,DDL) speak Spanish. Two studies $[42,43]$ were excluded from the meta-analysis because they investigated the use of non-internationally available porcine surfactants.

One of these surfactants is produced and only marketed in Cuba; the other one is a new, low-cost preparation only marketed in Brazil. The Brazilian surfactant has been compared versus controls treated with a mix of poractant- $\alpha$ and beractant [42]. The 14 studies included in the meta-analysis investigated poractant- $\alpha$ versus the above-mentioned bovine surfactants: five studies were conducted in North-America, five in Europe and four in Asia. A total of 1491 neonates were enrolled. Seven out of 14 studies were multicentre, although populations were relatively small (between 15 and 99 patients/arm). The use of antenatal steroids varied widely across the studies (from 25.9 to $100 \%$ ), while all studies, apart from two, $[37,38]$ enrolled babies with mean gestational age $\leq$
30 weeks. Two studies investigated the effect of poractant- $\alpha$ versus two distinct bovine surfactants in a three-arms design: [28, 37] data from the arms treated with bovine surfactants have been aggregated for the meta-analysis, since earlier meta-analysis did not detect significant differences between bovine surfactants [9]. All studies, apart from two, [28, 39] investigated poractant $\alpha$ at the $200 \mathrm{mg} / \mathrm{kg}$ dose. One study [39] trialled beractant versus high dose $(200 \mathrm{mg} / \mathrm{kg})$ or low dose $(100 \mathrm{mg} / \mathrm{kg})$ poractant- $\alpha$ : data from $200 \mathrm{mg} / \mathrm{kg}$ arm have been used in the first analysis and data from both arms have been pooled together in the second analysis, irrespective of the dosage used.

Risk of bias evaluation is reported in the Additional file 1 . The studies performed mostly well in completeness of outcome analysis and reporting, but generally suffered from performance bias resulting from lack of blinding for interventions and outcome assessments 
(apart from one [39]). The methods of randomization and allocation concealment were unclear for the majority of studies. There seemed to be no significant Funnel plot asymmetry as reported in Additional file $1(p=$ 0.862 , Peters' test).

The first and second analyses compared $200 \mathrm{mg} / \mathrm{kg}$ of poractant- $\alpha$ and any doses of poractant- $\alpha$ versus 100 $\mathrm{mg} / \mathrm{kg}$ bovine surfactants, respectively: their results are very similar as the addition of trials irrespective of poractant- $\alpha$ dose only added $2-3$ trials. Twelve trials reported mortality data studying $200 \mathrm{mg} / \mathrm{kg}$ poractant $\alpha$ and 14 studying any dose of poractant- $\alpha$. There appeared to be no significant differences between poractant- $\alpha$ and bovine surfactants in terms of mortality in both analyses (Fig. 2a: $p=0.164$; Fig. 2b: $p=0.077$ ). There is relevant heterogeneity within these studies: populations are probably not sufficiently large to reach statistical significance for this outcome. Twelve trials reported data on the composite $\mathrm{BPD} /$ mortality endpoint, studying poractant- $\alpha$ administered at a dose of $200 \mathrm{mg} / \mathrm{kg}$ and a further study evaluated this outcome studying poractant- $\alpha$ at a dose of $100 \mathrm{mg} / \mathrm{kg}$. The incidence of this outcome is significantly lower in neonates treated with $200 \mathrm{mg} / \mathrm{kg}$ poractant- $\alpha$ (Fig. 2c: $p<$ 0.001 ), and pooling together neonates treated with both doses (Fig. 2d: $p<0.001$ ).

Poractant- $\alpha$ appeared associated with significantly lower incidence of BPD both when considering studies administering it at $200 \mathrm{mg} / \mathrm{kg}$ (Fig. 3a: $p=$ 0.013 ) and when analyses were repeated pooling together patients receiving different doses (Fig. 3b: $p=$ $0.019)$.

Data about surfactant redosing were available in 11 and 12 trials, for the $200 \mathrm{mg} / \mathrm{kg}$ and any dose, respectively. Poractant- $\alpha$ was associated with significantly lower incidence of surfactant retreatment in both analyses (Fig. 3c: $p<0.0001$; Fig. 3d: $p<0.0001)$. Significant heterogeneity is evident for this comparison, probably due to the different criteria triggering surfactant retreatment used across the trials.

Eleven trials reported airleaks data, evaluating poractant- $\alpha$ at a dose of $200 \mathrm{mg} / \mathrm{kg}$ and 13 studying any dose of poractant- $\alpha$, respectively. Poractant- $\alpha$ appeared associated with a significantly lower incidence of airleaks both at $200 \mathrm{mg} / \mathrm{kg}$ dosing (Fig. 4a: $p=0.006$ ) and when pooling together the patients across arms with different dosing regimens (Fig. 4b: $p=0.01$ ).

Data about pulmonary haemorrhage were available in ten and eleven trials for the analysis with $200 \mathrm{mg} / \mathrm{kg}$ poractant- $\alpha$ and any dose, respectively. There is a nearly significant reduction of pulmonary haemorrhage with the use of $200 \mathrm{mg} / \mathrm{kg}$ poractant- $\alpha$ (Fig. 4c: $p=0.051$ ), while this reduction becomes significant when analysis was done pooling together patients receiving different doses of poractant- $\alpha$ (Fig. $4 \mathrm{~d}: p=0.038$ ). Significant heterogeneity was detected only for the analysis of any dose

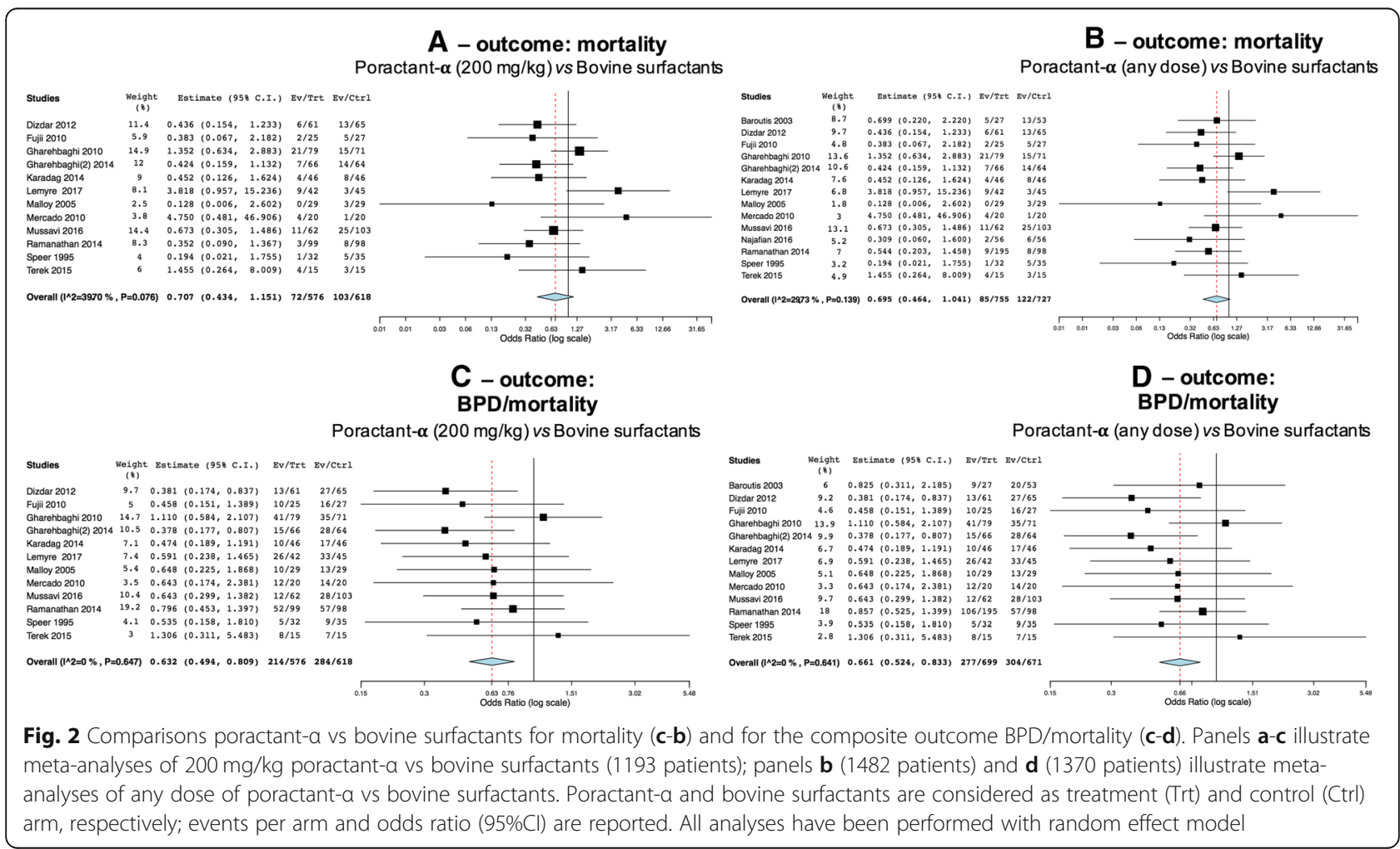




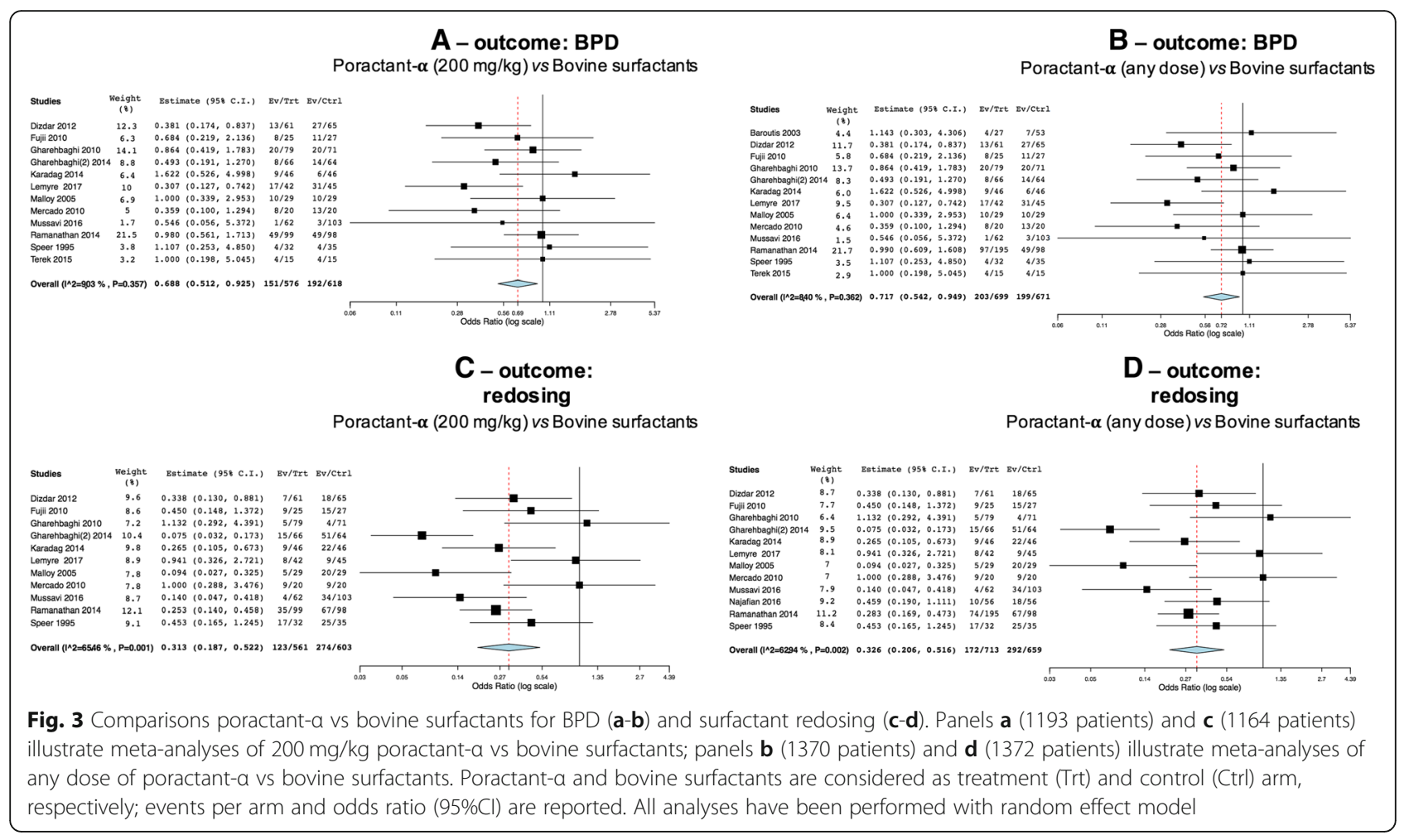

of poractant- $\alpha$ versus bovine surfactants, due to the inclusion of one more study [38] in the analysis.

Gestational age is significantly associated with effect size of poractant- $\alpha$ on BPD (coefficient: 0.308 (95\% CI: 0.063, $0.554) ; p=0.014$ ) and on surfactant retreatment (coefficient:
-0.311 (95\% CI: $-0.595,-0.028$ ); $p=0.031$ ): the age - response relationships are shown in Fig. 5. Prenatal steroids and the dose of poractant- $\alpha$ are not significantly associated with effect size for any outcome comparison ( $p$ always > 0.05), as shown in the Additional file 1.

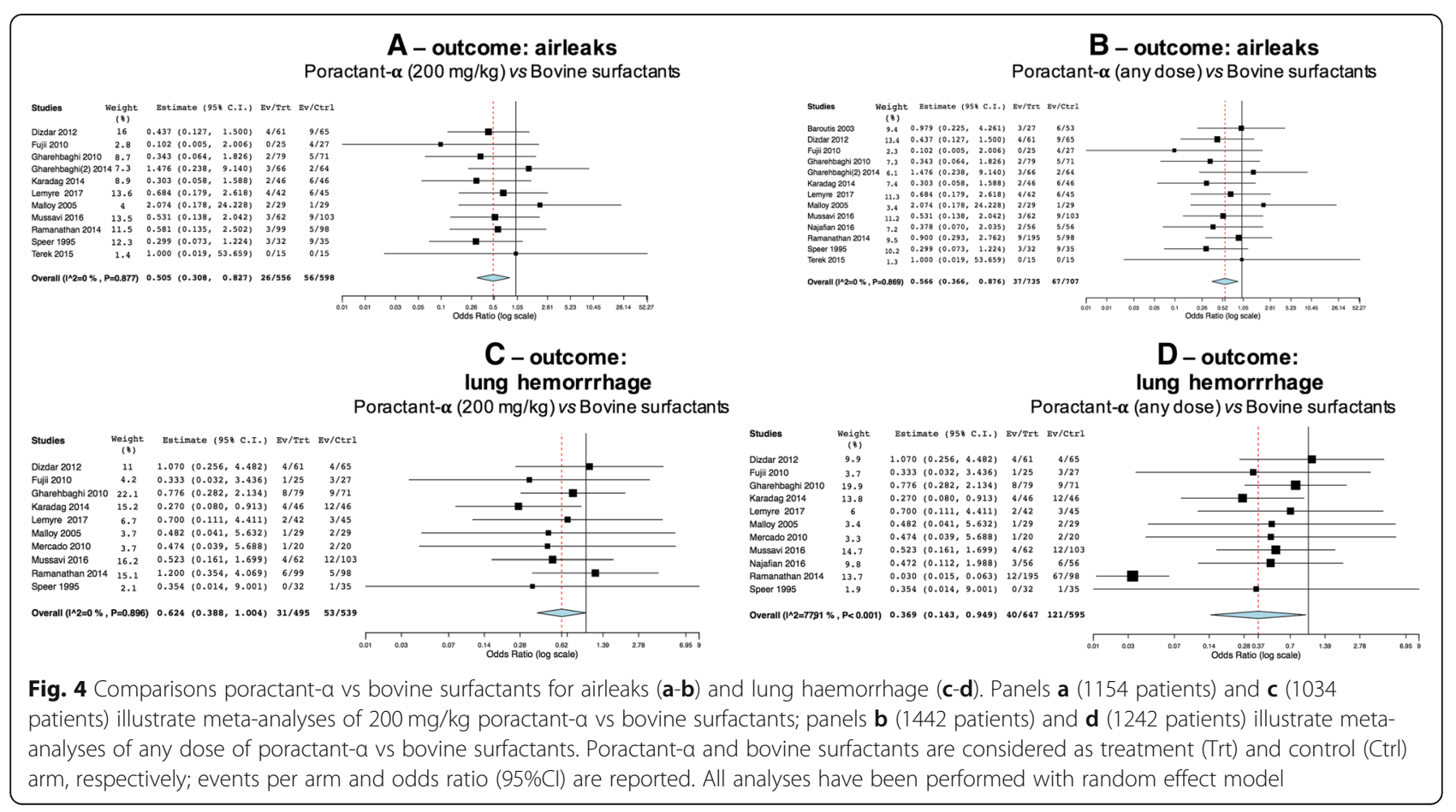




\section{Discussion}

\section{Summary of evidence}

Three porcine surfactants (butantan, poractant- $\alpha$ and surfacen) currently exist, but only poractant- $\alpha$ is internationally marketed and has been compared to bovine surfactants in several trials. Our meta-analysis compared for the first time the effects of poractant- $\alpha$ with all bovine surfactants, based on an aggregate sample larger than the ones used in previous meta-analyses [9, 49]. This has been possible because the meta-analysed studies compared poractant- $\alpha$ with the three more commonly available bovine surfactants (beractant, bovactant, BLES), which have been already deemed to be clinically equivalent [9]. This is not surprising given the biochemical and pharmacological similarities between bovine surfactants (Table 1). Moreover, we have been able to include four studies, [34, 37, 38, 41] that were still unpublished or under classification at the time of the latest Cochrane review [9].

Our meta-analysis is also much larger than that published by Singh et al., as they could only include five trials comparing poractant- $\alpha$ and only with beractant [49].

In summary, our findings show a trend for reduced mortality and significantly reduced incidence of BPD/ mortality, BPD, airleaks, lung haemorrhage and need for retreatment in neonates treated with poractant- $\alpha$ at 200 $\mathrm{mg} / \mathrm{kg}$ dose, compared to those treated with bovine surfactants. Our findings also showed that effect size for $\mathrm{BPD}$ is higher at the lowest gestational ages. Conversely, the effect size for surfactant redosing is higher at the highest gestational ages.

These results are only partially similar to those of earlier works but they are also stronger. In fact, previous meta-analyses: 1) included four trials (and about 400 neonates) less than us, which accounts for about $25 \%$ of the studied population; 2) analysed only one type of bovine surfactant $[9,49]$ or have been performed with a network design, due to the lack of comparisons between each surfactant; [50] 3) could not aggregate trials as we did, since equivalence between bovine surfactants had been not demonstrated yet; [9] 4) did not analyse the effect of possible confounders, such as antenatal steroids, gestational age or poractant- $\alpha$ dose; 5) did not compare the biochemical and pharmacological features out of each surfactant and did not consider the clinical results in light of the biological background. Ours was intended to be not only a statistical work but also a multidisciplinary project coupling clinical outcomes with their biological plausibility.
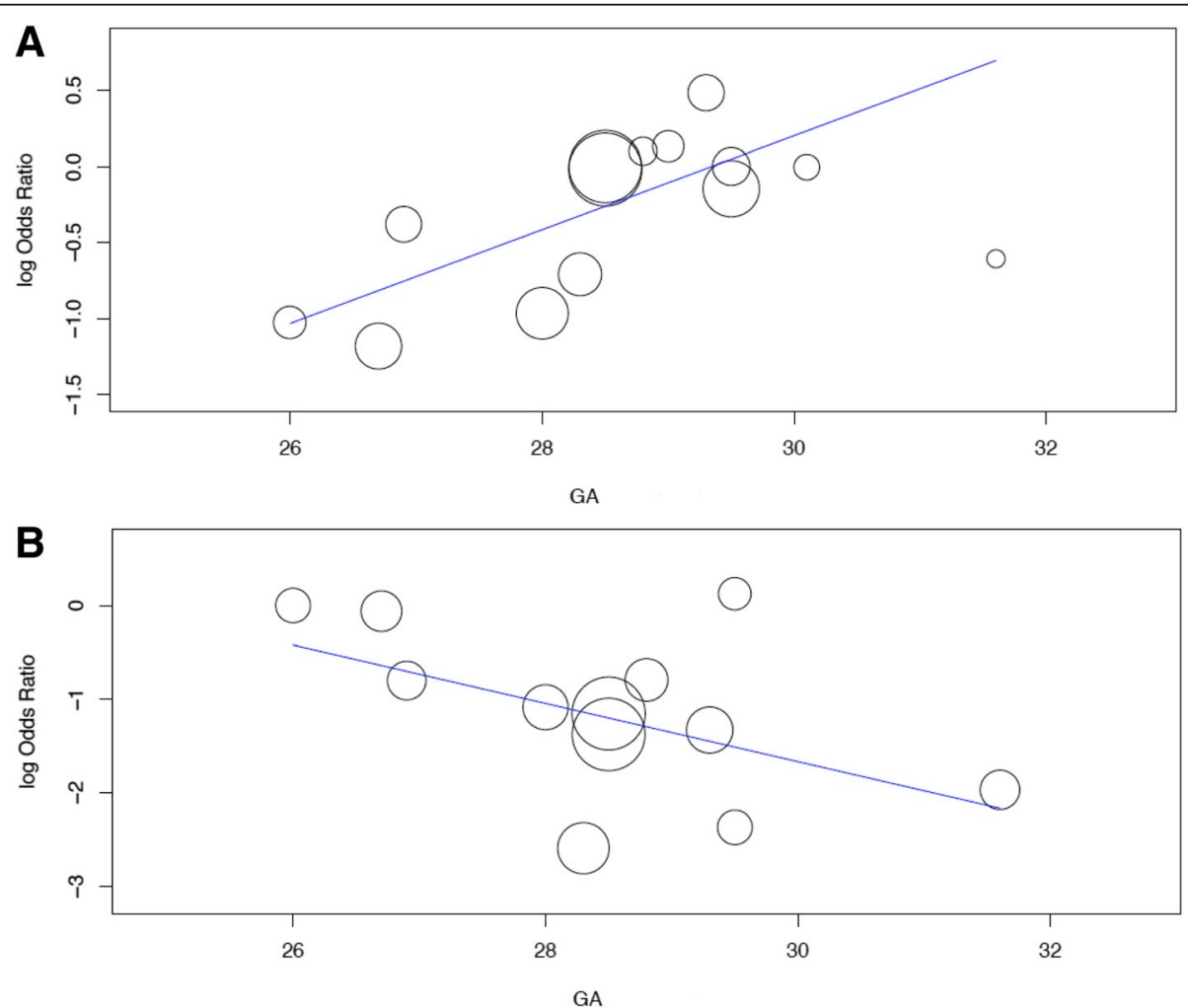

Fig. 5 Meta-regressions plots. Gestational age (GA) - response relationships for the incidence of bronchopulmonary dysplasia (Panel a; the lower the gestational age, the lower the odds) and the need for surfactant retreatment (Panel $\mathbf{b}$; the higher the gestational age, the lower the odds) are shown. Gestational age is expressed in weeks 


\section{Biological and physiopathological plausibility}

Overall, the evidence is not sufficiently robust to determine if porcine or bovine surfactants are better in terms of mortality. There seems to be a trend in favour of poractant- $\alpha$, but definite conclusions will require larger studies. In fact, when we increased the population by adding the few studies on $100 \mathrm{mg} / \mathrm{kg}$ poractant- $\alpha$, the odds ratio was at the border of significance, despite the use of a lower dose. However, these were only three studies, based on a few babies and much larger studies are needed for such a complex outcome. In fact, for preterm neonates, who often remain hospitalized for several weeks or months, in-hospital mortality is an extremely complex outcome and may be influenced by other additional factors. This may explain the observed heterogeneity.

In fact, surfactants reduce surface tension, improving compliance and gas exchange. Thus, surfactants can reduce early mortality due to respiratory failure. However, it is unclear how surfactants could influence several non-pulmonary life-threatening complications (i.e.: intracranial haemorrhage, necrotizing enterocolitis, late-onset sepsis) in this highly vulnerable population $[45,51]$.

Our findings suggest that poractant- $\alpha$ (at $200 \mathrm{mg} / \mathrm{kg}$ ) may be associated with lower incidence of $\mathrm{BPD} /$ mortality and BPD. This may be understandable as a more efficacious surfactant should reduce the duration of ventilation and its deleterious effects on the developing lung. We did not evaluate the effect of surfactants on the oxygenation, ventilatory parameters, ventilator-free days or similar measures, as these were inconsistently defined in the trials, and, when reported, summarized in different ways, making the data unsuitable for quantitative aggregation. Furthermore, ventilatory strategies significantly vary across different neonatal units [52].

Neonates treated with poractant- $\alpha$ (at $200 \mathrm{mg} / \mathrm{kg}$ ) appeared to have better short-term respiratory outcomes compared to those treated with bovine surfactants, and, in particular, lower incidence of airleaks, lung haemorrhage and need for retreatment. These improved outcomes may be explained with a higher poractant- $\alpha$ effectiveness or may be due to the higher deliverable dose. It can be hypothesized that poractant- $\alpha$ may resist longer to hydrolysis and injury caused by secretory phospholipase A2 and other inflammatory agents, which are often present especially in extremely preterm neonates $[53,54]$. As the mean time needed for preterm neonates to produce enough endogenous surfactant is about 4 days, [55] an exogenous surfactant able to remain effective for a longer time may not require re-treatment. Moreover, exogenous surfactant stimulates endogenous production [56] and an efficient surfactant should be also capable of reducing the need for aggressive ventilation, avoiding its pro-inflammatory effect [57].

The hypothesized higher efficiency of poractant- $\alpha$ may be related to two factors: 1) the phospholipid profile, as some minor phospholipids may protect surfactant from its catabolism; [58] 2) the hydrophobic protein content, especially for surfactant protein-B, which is needed to stabilize surfactant film and allow its spreading at the air/liquid interface and also to protect phospholipids from phospholipase- induced hydrolysis [59, 60]. While more basic research is needed to identify the best lipid profile, the role of surfactant proteins is well known, as older synthetic protein-free surfactants are clinically inferior to animal-derived surfactants, which at least carry some amounts of proteins [8].

The higher dose of poractant- $\alpha$ is also likely to explain these results. In fact, administering 200 instead of 100 $\mathrm{mg} / \mathrm{kg}$ would provide lungs with more biophysically active molecules and enough surfactant may remain active in the alveoli, even in the presence of surfactant-injuring and inflammatory agents [54]. Pharmacokinetic and clinical data show that the $200 \mathrm{mg} / \mathrm{kg}$ poractant- $\alpha$ regimen should be preferred to the $100 \mathrm{mg} / \mathrm{kg}$ one, [6] since the higher dose provide a longer half life, less retreatment and a better clinical response in terms of oxygenation $[61,62]$. It is important to note that higher doses are not easy to administer with bovine surfactants given their lower concentration and higher viscosity, [63] requiring higher volumes of administration: larger doses may cause lung oedema, potentially increasing the need for more aggressive ventilation and this may trigger a vicious cycle. The analysis for surfactant retreatment showed significant heterogeneity and this is possibly due to the different redosing criteria used in the different trials. This reflects the variability in practice existing across neonatal units, [64] hence the decision to analyse the data in a pragmatic way.

Effect sizes for BPD and surfactant retreatment are significantly associated with gestational age: poractant- $\alpha$ reduces more significantly the risk of BPD at the lowest gestational ages, while it is more effective in reducing need for redosing at highest gestational ages. Prenatal steroids use varied widely across the studies, however our analysis demonstrated that antenatal steroids are not associated with effect size for any outcome comparison. Thus, the superiority of one surfactant over the others does not seem to be related to steroid prophylaxis. Our main results were unchanged analysing any dose of poractant- $\alpha$ (i.e.: when we aggregated trials of low-dose poractant- $\alpha$ and when we performed meta-regression models adjusting for poractant- $\alpha$ dose). However, these analyses have been performed considering data from only 2-3 trials and few babies treated with low poractant- $\alpha$ dose $[28,38,39]$. Therefore, there is not 
enough evidence to determine whether the administration of poractant- $\alpha$ at a dose of $100 \mathrm{mg} / \mathrm{kg}$ provides advantages over bovine surfactants.

Our results are methodologically stronger than those provided by previous meta-analyses for the reasons described above. In particular, bovine surfactants have been previously demonstrated to be clinically equivalent, and this equipoise is understandable in the light of their composition (Table 1). Our findings are also novel as they allowed to advance knowledge in the field and answer the question "what is the best surfactant at its licensed dose?". Relevant knowledge advancements provided by the present work are summarised in Table 2.

\section{Limitations}

Although some of our results are statistically, biologically and clinically significant, they should be interpreted cautiously because of the following limitations. We have chosen outcomes easily defined and reported. The shared outcome definitions allow to aggregate data, but small differences are present across studies, such as the criteria for BPD definition or surfactant re-treatment. Thus, we decided to perform a pragmatic meta-analysis, as differences reflect the reality of neonatal care across hospitals using different BPD definitions and surfactant re-treatment criteria [65]. Moreover, studied populations were relatively small and the quality of the studies varied: the potential for bias was detected in almost every trial and this can impact on the results of meta-analysis.

We focused on short term respiratory outcomes as these are the easiest to define and are targeted in the majority of studies, although they may not necessarily be associated with long term respiratory outcomes [66]. However, these outcomes may represent life-threatening situations or be associated with significant burden of care.

As the majority of studies investigated poractant- $\alpha$ at $200 \mathrm{mg} / \mathrm{kg}$, the evidence is not sufficiently robust to draw any conclusion about the low dose poractant- $\alpha$. However, given the known clinical and pharmacokinetic advantages of $200 \mathrm{mg} / \mathrm{kg}$ dose of poractant- $\alpha$, [61, 62] it might seem unethical to design a trial only to verify if the $200 \mathrm{mg} / \mathrm{kg}$ dose or the biochemical composition is responsible for the superiority of poractant- $\alpha$. From the other hand a trial with doses higher than $100 \mathrm{mg} / \mathrm{kg}$ of bovine surfactant has never been conducted and would be almost technically impossible. In fact, as bovine surfactants are less concentrated, higher doses can cause lung edema requiring more aggressive ventilation. Hemodynamic troubles potentially leading to intracranial hemorrhage and other complications have already been described with usual doses of bovine surfactants [33]. For these reasons, also the more recent animal studies only investigated bovine surfactants at their licensed dose [67].

We did not perform an individual patient meta-analysis but rather meta-regressions and therefore some results might be subjected to the limitations of this technique, including some confounders that may have not been captured [22].

We did not perform analyses about any extra-pulmonary outcome, as this is the subject of another presently ongoing project. Moreover, it is a matter of debate how surfactant may influence these outcomes, especially in an era of antenatal steroids use and less invasive ventilation policies $[45,51]$.

We used a random-effects model which creates an average of different treatment effects, not an estimate of

Table 2 Knowledge advancement on the topic

\begin{tabular}{|c|c|c|}
\hline Outcome & Cochrane Meta-analysis 2015 [9] & Present work \\
\hline Mortality & 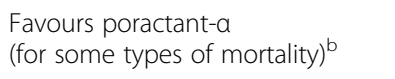 & Trend favouring poractant- $a$ \\
\hline BPD & No difference & Favours poractant-a \\
\hline Airleaks & No difference & Favours poractant- $a$ \\
\hline Lung haemorrhage & No difference & Favours poractant-a \\
\hline BPD/mortality & Favours poractant- $a$ & Favours poractant- $a$ \\
\hline Re-treatment & Unknown or favours poractant- $a^{c}$ & Favours poractant-a \\
\hline Effect of confounder & Cochrane Meta-analysis 2015 & Present work \\
\hline Prenatal steroids & Unknown & Not significant \\
\hline Gestational age & Unknown & $\begin{array}{l}\text { Influences effect size on BPD } \\
\text { and need for retreatment }\end{array}$ \\
\hline Poractant-a dose & Unknown & Unknown \\
\hline
\end{tabular}

Conclusions from the present work and the earlier meta-analysis [9] are compared. New insights are in italic texts

${ }^{a}$ including both the comparisons lavage bovine and minced bovine vs minced porcine surfactant - ${ }^{b}$ only for in-hospital mortality. The overall neonatal mortality did not present any difference - ${ }^{c}$ This outcome was analysed only for the comparison bovine minced vs porcine minced surfactants 
a single true treatment effect, and this may influence the interpretation of the results. This choice was however correct due to the relevant heterogeneity detected.

Finally, we based our work on the "clinical equivalence" of bovine surfactants according to the available evidence and to the biological/pharmacological differences between surfactants [9]. Combining different drugs into a single group may be seen as a limitation, although it is supported by the similar pharmacological and biochemical features of bovine surfactants. These features were not totally new. However, data about surfactant pharmacological and biochemical properties were dispersed in several papers or industrial databases and not always fully or easily available to the readers. Our work in this area consisted in collecting these data, make them comparable and easily available as much as possible and finally linked to the clinical data obtained by the meta-analysis. This last work had never been done and it is important to fully understand the available clinical evidence.

\section{Conclusions}

Poractant- $\alpha$ (at $200 \mathrm{mg} / \mathrm{kg}$ dose) is associated with better short term respiratory outcomes when compared to bovine surfactants at their licensed dose in preterm neonates with RDS. The effect of poractant- $\alpha$ in terms of $\mathrm{BPD}$ reduction is greater at lowest gestational age, while the effect on the need for retreatment is greater at highest gestational ages.

\section{Additional file}

Additional file 1: Table S1. Characteristics of studies included in the systematic review and in the meta-analysis. Figure $\mathbf{S 1}$. Results of bias assessment. Table S2. Additional meta-regression results. (DOCX 2973 kb)

\section{Abbreviations}

BPD: bronchopulmonary dysplasia; ESPR: European Society for Paediatric Research; OR: odds ratio; PAS: Paediatric Academic Societies; RDS: Respiratory distress syndrome

\section{Funding}

There was no funding source for this study.

\section{Availability of data and materials}

All raw data generated or analysed during this study are included in this published article [and its supplementary information files].

\section{Authors' contribution}

Dr. AT designed the work, substantially participated to data acquisition and interpretation. He revised the manuscript critically for important intellectual content. Dr. LDM substantially participated to data acquisition and analysis. She revised the manuscript critically for important intellectual content. A/ Prof. DDL conceived the work, substantially participated to data acquisition, analysis and interpretation. He drafted the manuscript. All authors approved the final version of the manuscript and agree to be accountable for all the work.

\section{Ethics approval}

Not applicable as this is a review and meta-analysis. Trials meta-analysed have all received their original ethical approval.

\section{Consent for publication}

Not applicable

\section{Competing interests}

A/Prof. D. De Luca has received grants for research and educational projects from Chiesi Pharmaceuticals spa and ABBVIE inc. He also received travel grants from ABBVIE inc. He served as consultant and lecturer for both Chiesi Pharmaceuticals spa and ABBVIE inc. Finally, he has been member of the external advisory board for both Chiesi Pharmaceuticals spa and ABBVIE inc These companies produce two surfactants analysed in the paper, but they had no role in design and conduct of the study; collection, management, analysis, and interpretation of the data; preparation, review, approval of the manuscript or decision to submit it for publication. The other authors declare no competing interests.

\section{Publisher's Note}

Springer Nature remains neutral with regard to jurisdictional claims in published maps and institutional affiliations.

\section{Author details}

'Department of Molecular and Clinical Pharmacology, University of Liverpool, Liverpool, UK. ${ }^{2}$ Critical Care Unit, Whiston Hospital, St Helens and Knowsley Teaching Hospitals, Merseyside, UK. ${ }^{3}$ Division of Pediatrics and Neonatal Critical Care, Medical Center "A. Béclère", South Paris University Hospitals, Assistance Publique-Hôpitaux de Paris (APHP), Paris, France.

${ }^{4}$ Physiopathology and Therapeutic Innovation Unit, INSERM U999, South Paris-Saclay University, Paris, France.

Received: 22 October 2018 Accepted: 6 January 2019 Published online: 06 February 2019

\section{References}

1. Boghossian NS, Geraci M, Edwards EM, et al. Morbidity and Mortality in Small for Gestational Age Infants at 22 to 29 Weeks' Gestation. Pediatrics. 2018;141(2). https://doi.org/10.1542/peds.2017-2533.

2. Claireaux AE. Hyaline membrane in the neonatal lung. Lancet. 1953;265: 749-53.

3. De Luca D, van Kaam AH, Tingay DG, et al. The Montreux definition of neonatal ARDS: biological and clinical background behind the description of a new entity. Lancet Respir Med. 2017;5:657-66.

4. Subramaniam P, Ho JJ, Davis PG. Prophylactic nasal continuous positive airway pressure for preventing morbidity and mortality in very preterm infants. Cochrane Database Syst Rev. 2016;6:CD001243.

5. De Paoli AG, Davis PG, Faber B, et al. Devices and pressure sources for administration of nasal continuous positive airway pressure (NCPAP) in preterm neonates. Cochrane Database Syst Rev. 2008;1:CD002977.

6. Sweet DG, Carnielli V, Greisen G, et al. European Consensus Guidelines on the Management of Respiratory Distress Syndrome - 2016 Update. Neonatology. 2017;111:107-25

7. Committee on Fetus and Newborn; American Academy of Pediatrics. Respiratory support in preterm infants at birth. Pediatrics. 2014;133:171-4.

8. Ardell S, Pfister RH, Soll R. Animal derived surfactant extract versus protein free synthetic surfactant for the prevention and treatment of respiratory distress syndrome. Cochrane Database Syst Rev. 2015;8:CD000144.

9. Singh N, Halliday HL, Stevens TP, et al. Comparison of animal-derived surfactants for the prevention and treatment of respiratory distress syndrome in preterm infants. Cochrane Database Syst Rev. 2015;12: CD010249.

10. Moher D, Liberati A, Tetzlaff J, et al. Preferred Reporting Items for Systematic Reviews and Meta-Analyses: The PRISMA Statement. BMJ. 2009;339:b2535.

11. Blanco O, Pérez-Gil J. Biochemical and pharmacological differences between preparations of exogenous natural surfactant used to treat respiratory distress syndrome: role of the different components in an efficient pulmonary surfactant. Eur J Pharmacol. 2007:568:1-15.

12. Echaide M, Autilio C, Arroyo R, Perez-Gil J. Restoring pulmonary surfactant membranes and films at the respiratory surface. Biochim Biophys Acta. 1859; 2017:1725-39. 
13. Lee C, Park MS, Kim JN, et al. Physical and biological activity of domestic product of modified bovine lung surfactant. J Korean Pediatr Soc. 1997:40:771-85.

14. Manzanares D, Fernández R, Moreno O, Torres O, Colomé H. Surfacen: Un surfactante natural para el tratamiento del síndrome del distress respiratorio neonatal. Rev Cuba Pediatr. 1997;69:3-10.

15. Chang M, Lu HY, Xiang H, Lan HP. Clinical effects of different ways of mechanical ventilation combined with pulmonary surfactant in treatment of acute lung injury/acute respiratory distress syndrome in neonates: a comparative analysis. Chin J Contemp Pediatr. 2016;18:1069-74.

16. Higgins JP, Altman DG, Gøtzsche PC, et al. The Cochrane Collaboration's tool for assessing risk of bias in randomised trials. BMJ. 2011;343:d5928.

17. Sterne JA, Sutton AJ, loannidis JP, et al. Recommendations for examining and interpreting funnel plot asymmetry in meta-analyses of randomised controlled trials. BMJ. 2011;343:d4002.

18. Sterne JAC, Egger M, Davey SG. Investigating and Dealing with Publication and Other Biases. In: Egger M, Davey Smith G, Altman DG, editors. Systematic reviews in health care: meta-analysis in context. $2^{\text {nd }}$ ed. London: BMJ Books; 2001. p. 189-208.

19. Roberts D, Brown J, Medley N, et al. Antenatal corticosteroids for accelerating fetal lung maturation for women at risk of preterm birth. Cochrane Database Syst Rev. 2017;3:CD004454.

20. Dargaville PA, Gerber A, Johansson S, et al. Incidence and Outcome of CPAP Failure in Preterm Infants. Pediatrics. 2016;138(1). https://doi.org/10.1542/ peds.2015-3985.

21. Wang H, Gao X, Liu C, et al. Morbidity and mortality of neonatal respiratory failure in China: surfactant treatment in very immature infants. Pediatrics. 2012;129:e731-40.

22. Thompson SG, Higgins JP. How should meta-regression analyses be undertaken and interpreted? Stat Med. 2002;21:1559-73.

23. Wallace BC, Schmid CH, Lau J, et al. Meta-analyst: software for metaanalysis of binary, continuous and diagnostic data. BMC Med Res Methodol. 2009;9:80.

24. Van Rhee HJ, Suurmond R, Hak T. User manual for Meta-Essentials: Workbooks for meta-analysis (Version 1.0) Rotterdam, The Netherlands: Erasmus Research Institute of Management. www.erim.eur.nl/researchsupport/meta-essentials. Accessed 8 Sept 2017.

25. Saeidi R, Hamedi A, Javadi A, et al. Comparison of side effect of survanta and curosurf in decreasing mortality due to respiratory distress syndrome (RDS) in premature infants admitted in NICU of Ghaem Hospital On 20062008. Ir J Neonatol. 2013;4:7-12

26. Saeidi R, Hamedi A, Javadi A, et al. Comparing effects of beractant and poractant alfa in decreasing mortality rate due to respiratory distress syndrome in premature infants. Tehran Univ Med J. 2011;68:644-8.

27. Akar S, Özalkaya E. Comparison of efficacy of beractant and poractant treatment performed with minimal invasive technique. J Perinat Med. 2015; 43:1071 [abstract].

28. Baroutis G, Kaleyias J, Liarou T, et al. Comparison of three treatment regimens of natural surfactant preparations in neonatal respiratory distress syndrome. Eur J Pediatr. 2003;162:476-80

29. Dizdar EA, Sari FN, Aydemir C, et al. A randomized, controlled trial of poractant alfa versus beractant in the treatment of preterm infants with respiratory distress syndrome. Am J Perinatol. 2012;29:95-100.

30. Fujii AM, Patel SM, Allen $R$, et al. Poractant alfa and beractant treatment of very premature infants with respiratory distress syndrome. J Perinatol. 2010; 30:665-70.

31. Gharehbaghi MM, Sakha SH, Ghojazadeh M, et al. Complications among premature neonates treated with beractant and poractant alfa. Indian J Pediatr. 2010;77:751-4.

32. Gharehbaghi MM, Yasrebi S. Comparing the Efficacy of two Natural Surfactants, Curosurf and Alveofact, in Treatment of Respiratory Distress Syndrome in Preterm Infants. Int I Women Health Reprod Sci. 2014;2:245-8

33. Karadag $N$, Dilli $D$, Zenciroglu $A$, et al. Perfusion index variability in preterm infants treated with two different natural surfactants for respiratory distress syndrome. Am J Perinatol. 2014;31:1015-22.

34. Lemyre B, Fusch C, Schmölzer GM, et al. Poractant alfa versus bovine lipid extract surfactant for infants $24+0$ to $31+6$ weeks gestational age: a randomized controlled trial. PLoS One. 2017;12:e0175922.

35. Malloy CA, Nicoski P, Muraskas JK. A randomized trial comparing beractant and poractant treatment in neonatal respiratory distress syndrome. Acta Paediatr. 2005;94:779-84.
36. Mercado W, Cristea I, Ali N, et al. Does surfactant type cause a differential proinflammatory response in preterm infants with respiratory distress syndrome? Adv Ther. 2010;27:476-82.

37. Mussavi M, Mirnia K, Asadollahi K. Comparison of the efficacy of three natural surfactants (Curosurf, Survanta, and Alveofact) in the treatment of respiratory distress syndrome among neonates: a randomized controlled trial. Iran J Pediatr. 2016;26:e5743.

38. Najafian B, Karimi-Sari H, Hossein Khosravi M, et al. Comparison of efficacy and safety of two available natural surfactants in Iran, Curosurf and Survanta in treatment of neonatal respiratory distress syndrome: a randomized clinical trial. Contemp Clin Trials Commun. 2016;3:55-9.

39. Ramanathan R, Rasmussen MR, Gerstmann DR, et al. A randomized, multicenter masked comparison trial of poractant alfa (Curosurf) versus beractant (Survanta) in the treatment of respiratory distress syndrome in preterm infants. Am J Perinatol. 2004;21:109-19.

40. Speer CP, Gefeller $\mathrm{O}$, Groneck $\mathrm{P}$, et al. Randomised clinical trial of two treatment regimens of natural surfactant preparations in neonatal respiratory distress syndrome. Arch Dis Child Fetal Neonatal Ed. 1995;72:F8-13.

41. Terek D, Gonulal D, Koroglu OA, et al. Effects of Two Different Exogenous Surfactant Preparations on Serial Peripheral Perfusion Index and Tissue Carbon Monoxide Measurements in Preterm Infants with Severe Respiratory Distress Syndrome. Pediatr Neonatol. 2015;56:248-55.

42. Rebello CM, Precioso AR, Mascaretti RS, Grupo Colaborativo do Estudo Brasileiro Multicêntrico de Surfactante. A multicenter, randomized, doubleblind trial of a new porcine surfactant in premature infants with respiratory distress syndrome. Einstein (Sao Paulo). 2014;12:397-404.

43. Sánchez-Mendiola M, Martínez-Nater OC, Herrera-Maldonado N, et al. Estudio controlado del tratamiento de la enfermedad de membrana hialina del recién nacido pretérmino con surfactante pulmonar exógeno (porcino vs. bovino). Gac Méd Méx. 2005;4:267-71 [article in Spanish].

44. Shalwitz RA. Comparison of treatment regimens of natural surfactant preparations in neonatal respiratory distress syndrome. Eur J Pediatr. 2004; 163:126.

45. Lutchman D. Have we been down this road before? J Perinatol. 2010;30:698-9.

46. Bancalari E. On "A randomized, multicenter masked comparison trial of poractant alfa (Curosurf) versus beractant (Survanta) in the treatment of respiratory distress syndrome in preterm infants" (Am J Perinatol 2004;21: 109-120). Am J Perinatol. 2004;21:307-9.

47. Logan S. Need to avoid bias in controlled trials. Arch Dis Child Fetal Neonatal Ed. 1995;73:F121.

48. Jeng MJ. Effects of two different exogenous surfactant preparations on serial peripheral perfusion index and tissue carbon monoxide measurements in preterm infants with severe respiratory distress syndrome. Pediatr Neonatol. 2015;56:211-2.

49. Singh N, Hawley KL, Viswanathan K. Efficacy of porcine versus bovine surfactants for preterm newborns with respiratory distress syndrome: systematic review and meta-analysis. Pediatrics. 2011;128:e1588-95.

50. Zhang L, Cao HY, Zhao S, et al. Effect of exogenous pulmonary surfactants on mortality rate in neonatal respiratory distress syndrome: a network meta-analysis of randomized controlled trials. Pulm Pharmacol Ther. 2015;34:46-54.

51. Holm B, Cummings JJ. Is there evidence for a mortality difference between exogenous surfactant preparations in neonatal RDS? J Appl Res. 2008;8:78-83.

52. van Kaam AH, Rimensberger $\mathrm{PC}$, Borensztajn $\mathrm{D}$, et al. Ventilation practices in the neonatal intensive care unit: a cross-sectional study. J Pediatr. 2010;157:767-71.

53. Been JV, Rours IG, Kornelisse RF, et al. Chorioamnionitis alters the response to surfactant in preterm infants. J Pediatr. 2010;156:10-5.

54. De Luca D, Baroni S, Vento G, et al. Secretory phospholipase A2 and neonatal respiratory distress: pilot study on broncho-alveolar lavage. Intensive Care Med. 2008;34:1858-64.

55. Cavicchioli P, Zimmermann L, Cogo PE, et al. Endogenous surfactant turnover in preterm infants with respiratory distress syndrome studied with stable isotope lipids. Am J Respir Crit Care Med. 2001;163:55-60.

56. Bunt JE, Carnielli VP, Janssen DJ, et al. Treatment with exogenous surfactant stimulates endogenous surfactant synthesis in premature infants with respiratory distress syndrome. Crit Care Med. 2000;28:3383-8.

57. Ranieri VM, Giunta F, Suter PM, et al. Mechanical ventilation as a mediator of multisystem organ failure in acute respiratory distress syndrome. JAMA. 2000;284:43-4. 
58. Berger A, Havet N, Vial D, et al. Dioleylphosphatidylglycerol inhibits the expression of type II phospholipase A2 in macrophages. Am J Respir Crit Care Med. 1999;159:613-8.

59. Danhaive $\mathrm{O}$, Chapin $\mathrm{C}$, Horneman $\mathrm{H}$, et al. Surface film formation in vitro by infant and therapeutic surfactants: role of surfactant protein B. Pediatr Res. 2015;77:340-6.

60. Hite RD, Grier BL, Waite BM, et al. Surfactant protein B inhibits secretory phospholipase A2 hydrolysis of surfactant phospholipids. Am J Physiol Lung Cell Mol Physiol. 2012;302:L257-65.

61. Cogo PE, Facco M, Simonato M, et al. Dosing of porcine surfactant: effect on kinetics and gas exchange in respiratory distress syndrome. Pediatrics. 2009;124:e950-7.

62. Cogo PE, Facco M, Simonato M, et al. Pharmacokinetics and clinical predictors of surfactant redosing in respiratory distress syndrome. Intensive Care Med. 2011:37:510-7.

63. Lu KW, Pérez-Gil J, Taeusch H. Kinematic viscosity of therapeutic pulmonary surfactants with added polymers. Biochim Biophys Acta. 1788;2009:632-7.

64. van Kaam AH, De Jaegere AP, Borensztajn D, et al. Surfactant replacement therapy in preterm infants: a European survey. Neonatology. 2011;100:71-7.

65. Hines D, Modi N, Lee SK, et al. Scoping review shows wide variation in the definitions of bronchopulmonary dysplasia in preterm infants and calls for a consensus. Acta Paediatr. 2017;106:366-74

66. Parad RB, Davis JM, Lo J, et al. Prediction of respiratory outcome in extremely low gestational age infants. Neonatology. 2015;107:241-8.

67. Ricci F, Salomone F, Kuypers E, Ophelders D, Nikiforou M, Willems M, Krieger T, Murgia X, Hütten M, Kramer BW, Bianco F. In Vivo Evaluation of the Acute Pulmonary Response to Poractant Alfa and Bovactant Treatments in LungLavaged Adult Rabbits and in Preterm Lambs with Respiratory Distress Syndrome. Front Pediatr. 2017;5:186. https://doi.org/10.3389/fped.2017. 00186.

Ready to submit your research? Choose BMC and benefit from:

- fast, convenient online submission

- thorough peer review by experienced researchers in your field

- rapid publication on acceptance

- support for research data, including large and complex data types

- gold Open Access which fosters wider collaboration and increased citations

- maximum visibility for your research: over $100 \mathrm{M}$ website views per year

At $\mathrm{BMC}$, research is always in progress.

Learn more biomedcentral.com/submissions 